\title{
Comprehensive analysis of the functional and prognostic value of E2F transcription factors in human prostate cancer through data mining and experimental validation
}

\author{
Decai Wang ${ }^{1 \#}$, Wensen Tang ${ }^{1 "}$, Pingbao Zhang ${ }^{2 \#}$, Zijian Liu ${ }^{3}$, Fang Lyu ${ }^{1}$, Yajun Xiao ${ }^{1}$, Dong Ni ${ }^{1}$, Pu Zhang ${ }^{1}$ \\ ${ }^{1}$ Department of Urology, Union Hospital, Tongji Medical College, Huazhong University of Science and Technology, Wuhan, China; ${ }^{2}$ Department \\ of Urology, Zhongshan Hospital, Fudan University, Shanghai, China; ${ }^{3}$ Department of Head and Neck Oncology and Department of Radiation \\ Oncology, Cancer Center and State Key Laboratory of Biotherapy, West China Hospital, Sichuan University, Chengdu, China \\ Contributions: (I) Conception and design: P Zhang; (II) Administrative support: D Ni; (III) Provision of study of patients: D Wang, W Tang, F Lyu; \\ (IV) Collection and assembly of data: D Wang, W Tang, P Zhang, Z Liu; (V) Data analysis and interpretation: D Wang, W Tang; (VI) Manuscript \\ writing: All authors; (VII) Final approval of manuscript: All authors. \\ "These authors contributed equally to this work. \\ Correspondence to: Dong Ni; Pu Zhang. Department of Urology, Union Hospital, Tongji Medical College, Huazhong University of Science and \\ Technology, 1277 Jiefang Avenue, Wuhan 430022, China. Email: dni@hust.edu.cn; d202081801@hust.edu.cn.
}

Background: A growing body of evidence shows that E2F transcription factors play a significant role in the tumorigenesis of prostate cancer. However, their functional and prognostic value has not been fully illustrated. Therefore, we used bioinformatics methods to further analyze the possible roles of E2F transcription factors in the development and progression of prostate cancer.

Methods: We explored the expression levels of E2F transcription factors using data from The Cancer Genome Atlas (TCGA) and Oncomine database in paired and unpaired samples. The clinical correlation and prognostic value of E2F transcription factors were assessed. Using the R package "pROC", we judged the diagnostic value of E2F transcription factors. The online website tool cBioPortal was also employed to find possible gene alterations of E2F transcription factors in samples from TCGA. The R package "clusterprofiler" was used to conduct functional analysis. Moreover, we also used the Tumor Immune Estimation Resource to search for the associations between E2F transcription factors and the infiltration levels of 6 kinds of immune cells. Finally, quantitative real-time polymerase chain reaction (PCR) was conducted to validate the expression levels of E2F transcription factors in human paired prostate tissues.

Results: E2F1/2/3/5 messenger RNA (mRNA) expression levels were higher in prostate cancer tissues than in normal tissues, while E2F4 and E2F6 mRNA expression levels were lower $(\mathrm{P}<0.05)$. All E2F transcription factors were associated with clinical parameters. Kaplan-Meier analysis revealed that E2F1/4/6/8 were notably associated with the overall survival of patients with prostate cancer $(\mathrm{P}<0.05)$. Receiver operating characteristic (ROC) curve results showed that except for E2F7, the other E2F transcription factors had diagnostic value for prostate cancer $(\mathrm{P}<0.05)$. We further found close associations between $\mathrm{E} 2 \mathrm{~F}$ transcription factors and the infiltration levels of immune cells. The results of quantitative real-time PCR were consistent with those from public databases.

Conclusions: E2F transcription factor family members are differentially expressed in prostate cancer and are significantly related to the prognosis of patients, suggesting that they may be adopted as biomarkers for prognosis prediction and the treatment of prostate cancer.

Keywords: E2F transcription factors; prostate cancer; bioinformatics analysis; prognosis

Submitted Aug 05, 2021. Accepted for publication Nov 18, 2021.

doi: $10.21037 /$ tcr-21-1532

View this article at: https://dx.doi.org/10.21037/tcr-21-1532 


\section{Introduction}

As one of the most common male malignancies in the United States, prostate cancer (PCa) is also the second leading cause of male-related cancer death (1). In recent years, the rate of $\mathrm{PCa}$ in Chinese men has gradually increased, and the age of onset has gradually become younger, which poses a serious threat to the health of Chinese men (2). Studies have shown that about $30 \%$ of men over 65 years are diagnosed with $\mathrm{PCa}$, and many patients are diagnosed in the middle and late stages (3). Although the prognosis of most PCa patients is relatively good, the prognosis of PCa patients who relapse or metastasize after treatment is poor. Various biomarkers have been reported to be used for the monitoring of prognosis and predicting the recurrence of $\mathrm{PCa}$, including preoperative prostate-specific antigen (PSA) level, Gleason scores, and lymph node invasion, among others. However, these markers are not cancer-specific and accurate, and it is difficult to make personalized postoperative follow-up plans based on them (4). Ultimately, the optimal window of time to control the disease passes, and recurrence and metastasis of PCa occur, thereby reducing the overall survival (OS) rate of patients. Therefore, the screening of markers related to PCa may contribute to correct clinical decision-making and improve the prognosis of patients with $\mathrm{PCa}$.

The E2F gene was discovered by Kovesdi et al. (5) when they were studying the interaction between the nuclear extracts of adenovirus-infected cells and the E2 promoter of adenovirus, a new type of gene family that transcriptionally encodes cytokines. As a family of transcription factor proteins, E2Fs can regulate cell differentiation, cell cycle, apoptosis, and DNA damage response by affecting downstream gene transcription (6-8). There are 8 members in the $E 2 F$ gene family, namely $E 2 F 1-E 2 F 8$, among which $E 2 F 3$ includes $E 2 F 3 a$ and $E 2 F 3 b$. Each E2F member has a certain degree of homology, and they constitute a complex transcriptional regulatory network in the cell. According to the molecular structure and transcription characteristics of $E 2 F s$, they can be divided into 2 groups: transcriptional activators and transcriptional repressors. Among them, $E 2 F 1 / 2 / 3 a$ are described as transcriptional activators, while $E 2 F 3 b$ and E2F4-E2F8 are described as transcriptional repressors. Current studies have found that members of the $E 2 F$ transcription factor family can affect the progression of $\mathrm{PCa}$ (9-12). However, there are few reports on the expression of E2Fs and their prognostic significance in PCa.

This study comprehensively analyzes the expression and prognostic role of $E 2 F$ transcription factor family members in $\mathrm{PCa}$ through public databases and experimental validation, so as to provide a theoretical basis for further research on their role in the diagnosis and treatment of PCa. We present the following article in accordance with the REMARK reporting checklist (available at https:// dx.doi.org/10.21037/tcr-21-1532).

\section{Methods}

\section{The Cancer Genome Atlas (TCGA)}

We downloaded the level 3 HTseq-FPKM RNA sequencing (RNA-seq) data of PRAD from TCGA. The RNA-seq data in FPKM format was converted into TPM format, and $\log 2$ transformation was performed to compare the expression among samples. The $\mathrm{R}$ package "ggplot2" in $\mathrm{R}$ version 3.6.3 (The R Foundation for Statistical Computing, Vienna, Austria) was also employed to draw the boxplots and line plots. The statistical analysis was conducted using the Wilcoxon rank -um test and Wilcoxon signed rank test for unpaired and paired samples, respectively. A P value $<0.05$ was considered to be statistically significant.

\section{Oncomine analysis}

Oncomine is a cancer microarray database and integrated data mining platform designed to promote discovery from genomewide expression analysis (http://www.oncomine. org). Oncomine currently contains 65 gene expression datasets comprising nearly 48 million gene expression measurements for researchers to use. We compared the messenger RNA (mRNA) expression levels of E2Fs in various kinds of tumors with those in normal tissues through Oncomine. Statistical analysis was conducted by Student's $t$-test. The threshold of $\mathrm{P}$ values and fold change were 0.01 and 2 , respectively.

\section{The association of E2Fs with clinical parameters and the prognosis of patients}

We also downloaded clinical and survival data from TCGA, consisting of 499 tumor samples to explore the association between the expression of the $E 2 F$ family and clinical parameters, such as tumor stage, age, serum level of prostate-specific antigen (PSA), and the prognosis of patients. The R package "survminer" was used for data visualization while the $\mathrm{R}$ package "survival" was used for statistical analysis. The statistical analysis methods were the Kruskal-Wallis test and log-rank test. A P value $<0.05$ was 
considered to be statistically significant.

\section{Diagnostic ability}

To judge the potential of E2Fs as diagnostic biomarkers between normal and tumor samples, we employed the $\mathrm{R}$ package "pROC" to generate receiver operating characteristic (ROC) curves with the data in TPM format from TCGA.

\section{cBioPortal}

cBioportal is an online website integrating data from 126 tumor genome studies, which includes large-scale cancer research projects, such as the International Cancer Genome Consortium (ICGC) and TCGA (http://www.cbioportal. org). The Prostate Adenocarcinoma dataset (TCGA, Firehose Legacy) containing data from 499 cases with pathology reports was identified for further analysis of E2Fs with cBioportal. We explored the gene alterations of E2Fs on the website.

\section{Gene Ontology (GO) and Kyoto Encyclopedia of Genes and Genomes (KEGG) analysis}

Through the newly developed website Gene Expression Profiling Interactive Analysis 2 (GEPIA2), which is used for analyzing the RNA-seq data from TCGA database, we found the top 20 similar genes of every gene in the E2F family in the PRAD dataset. We conducted GO and KEGG analysis with these genes using the $\mathrm{R}$ packages "clusterProfiler" and "org.Hs.eg.db". The threshold of an adjusted $\mathrm{P}<0.05$ and $q$ value $<0.2$ were considered to indicate statistical significance.

\section{Tumor Immune Estimation Resource (TIMER)}

TIMER is a powerful web server used to comprehensively explore the molecular characterization of tumor-immune interactions. This tool allows the users to interactively explore the relationships between gene expression and immune infiltrates. We determined the associations between the expression levels of E2Fs and immune infiltrates. A P value $<0.05$ was considered to be statistically significant.

\section{Human specimens and real-time polymerase chain reaction}

Human prostate samples were obtained from 23 patients undergoing radical prostatectomy. The study was conducted in accordance with the Declaration of Helsinki (as revised in 2013), and the protocol was approved by the Ethics Committee of Wuhan Union Hospital, Tongji Medical College, Huazhong University of Science and Technology, Hubei, China. Total RNA was extracted from the tissues of 23 frozen prostate specimens using TRIzol reagent (Invitrogen, 15596026) according to the manufacturer's protocol. According to the manufacturer, a SYBR Green One-Step qRT-PCR Kit (Invitrogen, 11736059) was used to measure total RNA (100 ng).

\section{Statistical analysis}

The values of different groups are represented by the mean \pm SD (standard deviation). A paired, two-sided Student's $t$-test was used to compare differences between two groups. Statistical significance was analyzed by SPSS 22.0 software. $\mathrm{P}<0.05$ was considered statistically significant.

\section{Results}

\section{The mRNA expression levels of E2Fs between normal and tumor tissues}

We extracted the mRNA expression levels of E2Fs from the data downloaded from TCGA and the Oncomine database. For the unpaired tissues from TCGA, E2F1, E2F2, E2F3, and $E 2 F 5$ were up-regulated in the tumor tissues while E2F4 and E2F6 were down-regulated. Moreover, no significant difference was observed in the expression levels of $E 2 F 7$ and $E 2 F 8$ between normal and tumor tissues (Figure 1A). For paired tissues in TCGA, higher expression levels of $E 2 F 1 / 2 / 3 / 5$ were also observed in the tumor tissues, while higher expression levels of E2F4 and $E 2 F 6$ were found in normal tissues. As for $E 2 F 7$ and $E 2 F 8$, there was also no significant difference between normal and tumor samples (Figure 1B). The results from Oncomine were consistent with those from TCGA (Figure 1C).

\section{The association between E2Fs and the clinical parameters of patients with prostate cancer}

Using the clinical data from TCGA, we explored the relationships between E2Fs and clinical parameters. Except for those of E2F4 and E2F6, we found that in terms of tumor stage, the expression levels of E2Fs increased with the progression of tumors and that a statistical significance was observed in various stages of patients with $\mathrm{PCa}$ (Figure $2 A$ ). 

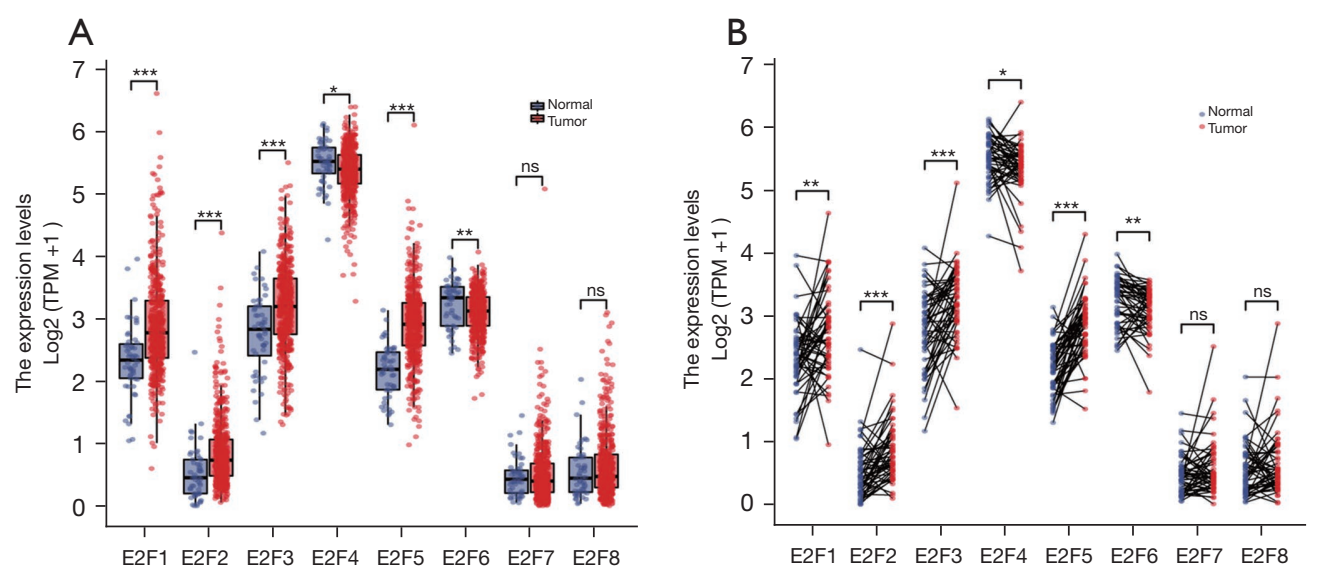

C

\begin{tabular}{|c|c|c|c|c|c|c|c|c|c|c|c|c|c|c|c|c|}
\hline & \multicolumn{2}{|c|}{ E2F1 } & \multicolumn{2}{|c|}{ E2F2 } & \multicolumn{2}{|c|}{ E2F3 } & \multicolumn{2}{|c|}{ E2F4 } & \multicolumn{2}{|c|}{ E2F5 } & \multicolumn{2}{|c|}{ E2F6 } & \multicolumn{2}{|c|}{ E2F7 } & \\
\hline Analysis type by cancer & \multicolumn{2}{|c|}{$\begin{array}{c}\text { Cancer } \\
\text { vs. } \\
\text { normal }\end{array}$} & \multicolumn{2}{|c|}{$\begin{array}{c}\text { Cancer } \\
\text { vs. } \\
\text { normal }\end{array}$} & \multicolumn{2}{|c|}{$\begin{array}{c}\text { Cancer } \\
\text { vs. } \\
\text { normal }\end{array}$} & \multicolumn{2}{|c|}{$\begin{array}{c}\text { Cancer } \\
\text { vs. } \\
\text { normal }\end{array}$} & \multicolumn{2}{|c|}{$\begin{array}{c}\text { Cancer } \\
\text { vs. } \\
\text { normal }\end{array}$} & \multicolumn{2}{|c|}{$\begin{array}{c}\text { Cancer } \\
\text { vs. } \\
\text { normal }\end{array}$} & \multicolumn{2}{|c|}{$\begin{array}{c}\text { Cancer } \\
\text { vs. } \\
\text { normal }\end{array}$} & \multicolumn{2}{|c|}{$\begin{array}{c}\text { Cancer } \\
\text { vs. } \\
\text { normal }\end{array}$} \\
\hline Bladder cancer & 2 & & 1 & & 2 & & & & & & & & & & 3 & \\
\hline Brain and CNS cancer & & 3 & 1 & 1 & & 1 & & 1 & 10 & 1 & & & 3 & 1 & 3 & \\
\hline Breast cancer & 10 & & 13 & 1 & 5 & & & & 2 & & & & 8 & & 4 & \\
\hline Cervical cancer & 2 & & 1 & 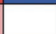 & 3 & & & & & & & & 1 & & 2 & \\
\hline Colorectal cancer & 4 & & & 8 & 5 & & & & 12 & & 5 & & 14 & & 1 & \\
\hline Esophageal cancer & 1 & & & 1 & 3 & & & & & & & & & & & \\
\hline Gastric cancer & 1 & & 2 & & 5 & & & & & & & & 1 & & & \\
\hline Head and Neck cancer & & 1 & & & 7 & & & 1 & 1 & & & & 4 & & & \\
\hline Kidney cancer & 1 & & 1 & & 1 & & 1 & & 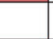 & & & & & & & 1 \\
\hline Leukemia & 3 & 4 & 1 & 5 & & 3 & 1 & & 2 & 3 & & & & & & 4 \\
\hline Liver cancer & 1 & & 1 & & 3 & & & & - & & & & & & 2 & \\
\hline Lung cancer & 4 & 1 & 6 & 1 & 11 & & & & 5 & & 1 & & 2 & & 5 & \\
\hline Lymphoma & & & 4 & & 1 & 1 & 3 & & 2 & 1 & & & 1 & & 3 & \\
\hline Melanoma cancer & 1 & & & & 2 & & & & & & & & & & & \\
\hline \multicolumn{17}{|l|}{ Myeloma cancer } \\
\hline Other cancer & 3 & & 2 & 1 & 4 & & & & 1 & & 1 & & 3 & & 2 & \\
\hline Ovarian cancer & 1 & & & & 2 & & & & 1 & & & & 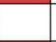 & & 1 & \\
\hline Pancreatic cancer & & & & & 2 & & & & 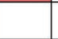 & & & & 2 & & 1 & \\
\hline Prostate cancer & 1 & & 1 & & 1 & & & 1 & 2 & & & 1 & & & & \\
\hline Sarcoma cancer & 1 & & & 3 & 3 & & & & & 2 & & & & & 2 & \\
\hline Significant unique analyses & 36 & 9 & 34 & 20 & 60 & 4 & 5 & 3 & 38 & 7 & 7 & 1 & 39 & 1 & 28 & 5 \\
\hline Total unique analyses & \multicolumn{2}{|c|}{449} & \multicolumn{2}{|c|}{403} & \multicolumn{2}{|c|}{438} & \multicolumn{2}{|c|}{455} & \multicolumn{2}{|c|}{457} & \multicolumn{2}{|c|}{206} & \multicolumn{2}{|c|}{256} & \multicolumn{2}{|c|}{376} \\
\hline
\end{tabular}

Figure 1 The expression levels of E2Fs in prostate cancer and normal tissues. (A) The expression levels of E2Fs in unpaired tissues; (B) the expression levels of E2Fs in paired tissues; $(\mathrm{C})$ the transcription levels of E2F factors in different types of cancers. ${ }^{*} \mathrm{P}<0.05$; ${ }^{* *} \mathrm{P}<0.01$; ${ }^{* * *} \mathrm{P}<0.001$. TPM, Transcripts Per Million; ns, not statistically significant.

In terms of $\mathrm{N}$ stage, we found that with the development of tumors, the expression levels of E2Fs increased, except for those of E2F4 and E2F6 (Figure $2 B$ ). We also found that the mRNA expression levels of $E 2 F 1 / 2 / 7$ were higher in patients over 60 years than in those under 60 years (Figure 2C). For patients with PSA $>4$, the expression levels of E2F1-E2F5 and E2F7-E2F8 were higher compared to those with PSA $<4$ (Figure 2D).

\section{The prognostic value of E2Fs in patients with $P C a$}

We further investigated the value of E2Fs in the OS of 

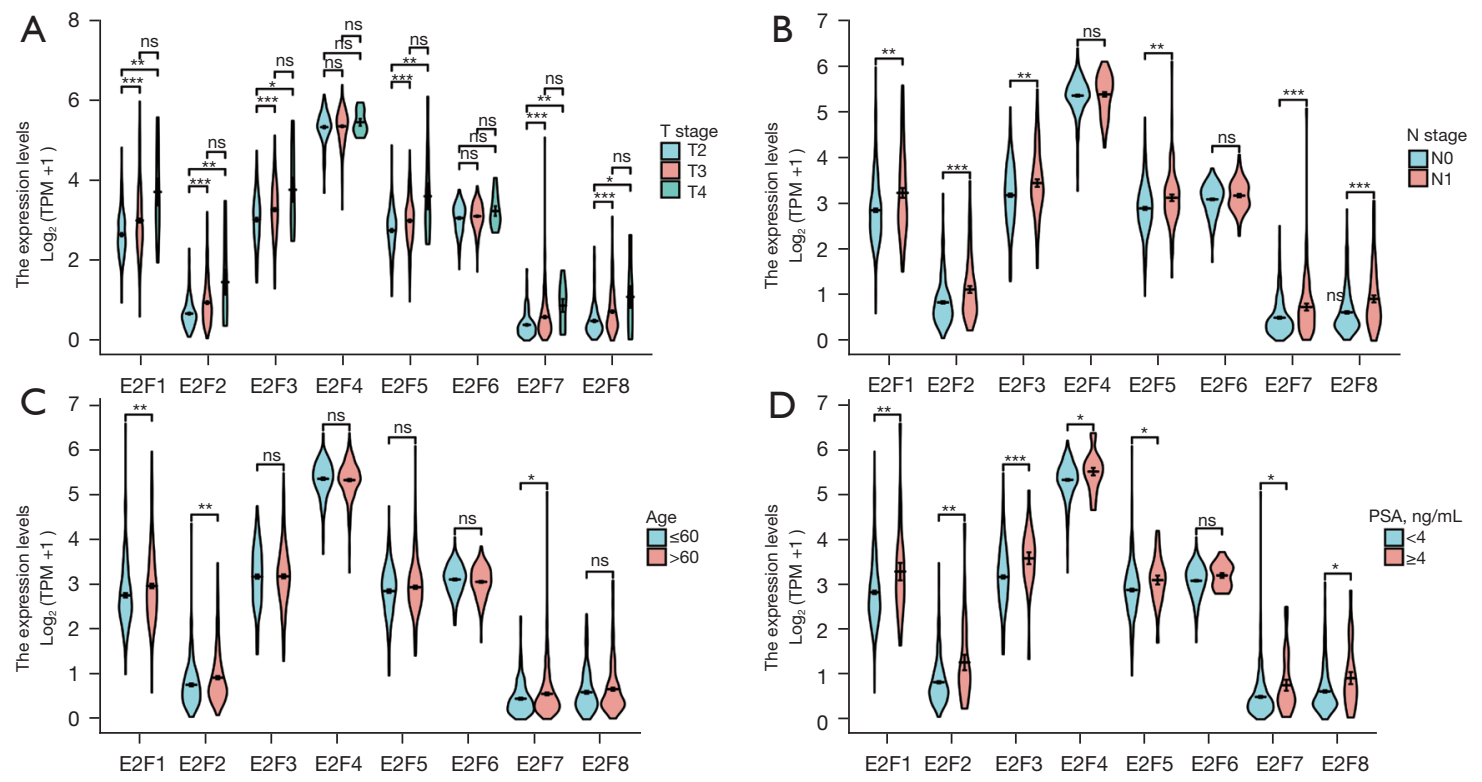

Figure 2 Correlation of E2F expression with tumor stage (A,B) age (C) and Prostate specific antigen (D) patients with PCa. PSA, prostate specific antigen; ${ }^{*} \mathrm{P}<0.05 ;{ }^{* *} \mathrm{P}<0.01 ;{ }^{* * *} \mathrm{P}<0.001$. TPM, Transcripts Per Million; ns: not statistically significant.

patients with PCa using Kaplan-Meier analysis. The survival data were downloaded from TCGA and consisted of 499 patients. The Kaplan-Meier curves revealed that E2F1/4/6/8 were markedly associated with the OS of patients with $\mathrm{PCa}$, while others were not $(\mathrm{P}<0.05$; Figure 3$)$.

\section{The diagnostic value of E2Fs in patients with PCa}

The diagnostic value of E2Fs was investigated using the R package "pROC". The results showed that $E 2 F 1$ [area under the curve $(\mathrm{AUC})=0.718], E 2 F 2(\mathrm{AUC}=0.710)$, $E 2 F 3(\mathrm{AUC}=0.676), E 2 F 4(\mathrm{AUC}=0.603), E 2 F 5$ (AUC $=0.861), E 2 F 6(\mathrm{AUC}=0.612)$, and $E 2 F 8(\mathrm{AUC}=0.550)$ were able to efficiently distinguish $\mathrm{PCa}$ tissues from normal prostate tissues (Figure 4), while E2F7 (AUC $=0.492$ ) lacked this ability (Figure 4A). However, receiver operating characteristic curve results showed that the AUC of PSA is only 0.659 (Figure $4 B$ ).

\section{The identification of gene alterations, coexpression, and neighbor gene network analysis}

We analyzed the alterations and coexpression of E2Fs by using the cBioPortal online tool for PCa (TCGA, Firehose Legacy). We found that in all 491 samples with mRNA data, the E2Fs were altered in 174 samples (35\%). E2F5 was the most frequently altered gene, which was altered in about $15 \%$ of patients. The alteration types of these genes included truncating mutation, missense mutation, deep deletion, amplification, mRNA high, and mRNA low. The frequency of gene alterations are presented in Figure $5 \mathrm{~A}$. The correlations among E2Fs were also calculated through analyzing their mRNA expression in cBioPortal. Spearman's correlation coefficient and Pearson's correlation coefficient were both implemented to explore their relationships. The results showed the following positive and significant correlations between the E2Fs: E2F1 with $E 2 F 2, E 2 F 7$, and $E 2 F 8 ; E 2 F 2$ with $E 2 F 7$ and $E 2 F 8$; $E 2 F 3$ with $E 2 F 5, E 2 F 7$, and $E 2 F 8$; E2F5 with $E 2 F 8$; and E2F7 with E2F8 (Figure 5B). Subsequently, a gene-gene interaction network was constructed by using the online analysis tool GeneMANIA (Figure 5C). Using this tool, we also explored the functions of E2Fs. The functions of $E 2 F s$ were transcription initiation from RNA polymerase II promoter, core promoter binding, initiation, G1/S transition of mitotic cell cycle, DNA integrity checkpoint, DNA-templated transcription, signal transduction by p53 class mediator, and regulatory region DNA binding. Moreover, we found 25 genes which were highly associated with E2Fs in physical interactions, colocalization, shared protein domains, pathway, prediction, and genetic interactions. 

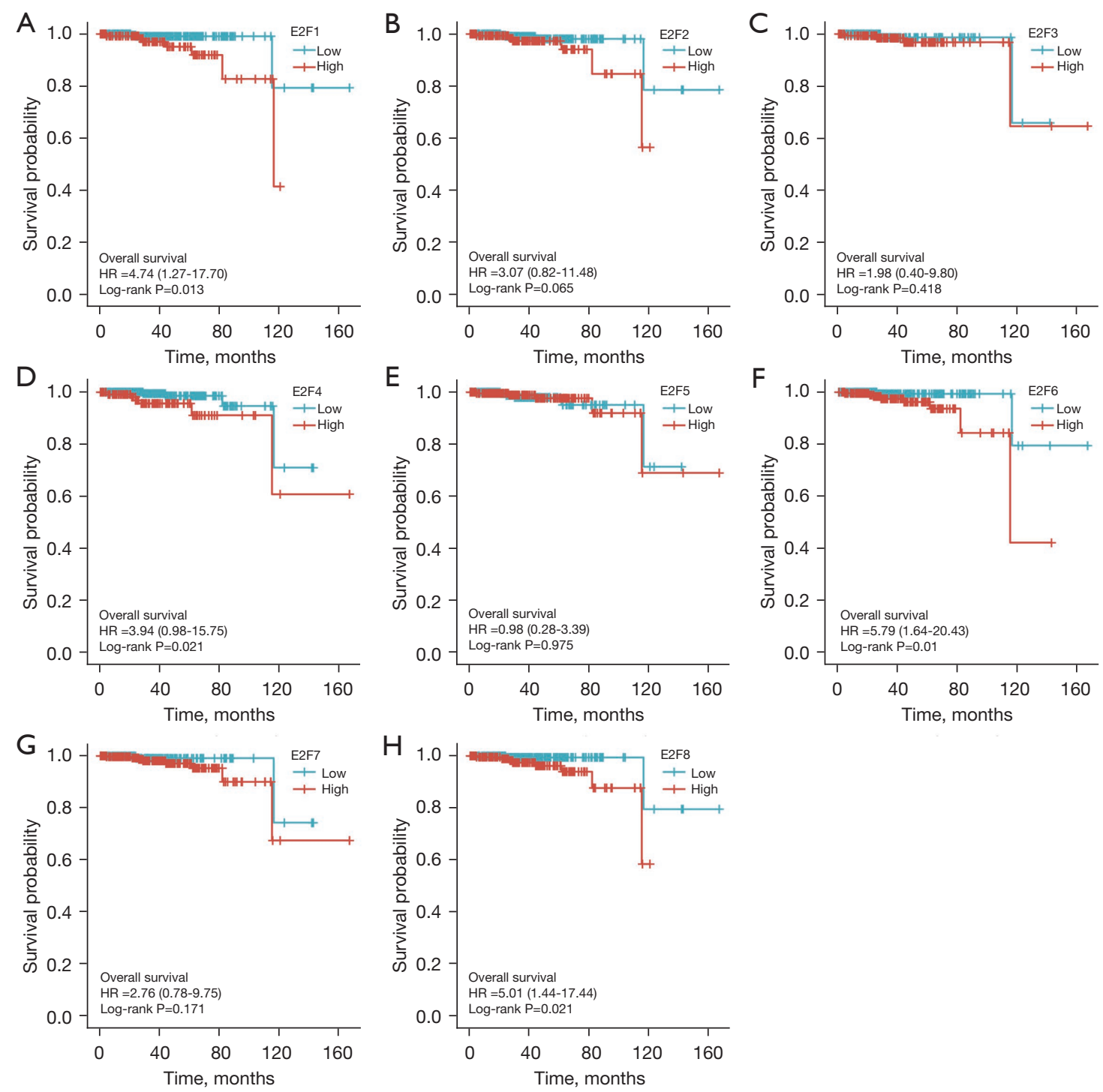

Figure 3 The prognostic value of E2F transcription factors in the patients with PCa. The Kaplan-Meier curves revealed that E2F1/4/6/8 $(\mathrm{A}, \mathrm{D}, \mathrm{F}, \mathrm{H})$ were markedly associated with the OS of patients with $\mathrm{PCa}$, while E2F2/3/5/7 (B,C,E,G) were not $(\mathrm{P}<0.05)$. OS, overall survival; HR, hazard ratio.

\section{Functional analysis of E2Fs and their related genes}

Using the R package "clusterProfiler", we used GO and KEGG analysis to explore the possible mechanism underlying the PCa with E2Fs and their related genes (Figure 6). The results demonstrated that in terms of biological process, these genes were mostly enriched in G0 to G1 transition, negative regulation of mitotic cell cycle, and mitotic DNA damage checkpoint. In terms of cellular component, they were mostly enriched in RNA polymerase II general transcription initiation factor activity, nuclear transcription factor complex, and lateral element. In terms of molecular function, they were mostly enriched in DNA-binding transcription activator activity, RNA polymerase IIspecific, transcription corepressor activity, and general transcription initiation factor activity. KEGG analysis showed that cellular senescence, cell cycle, transforming growth factor beta (TGF- $\beta$ ) signaling pathway, EpsteinBarr virus infection, $\mathrm{PCa}$, and microRNAs in cancer were enriched. 

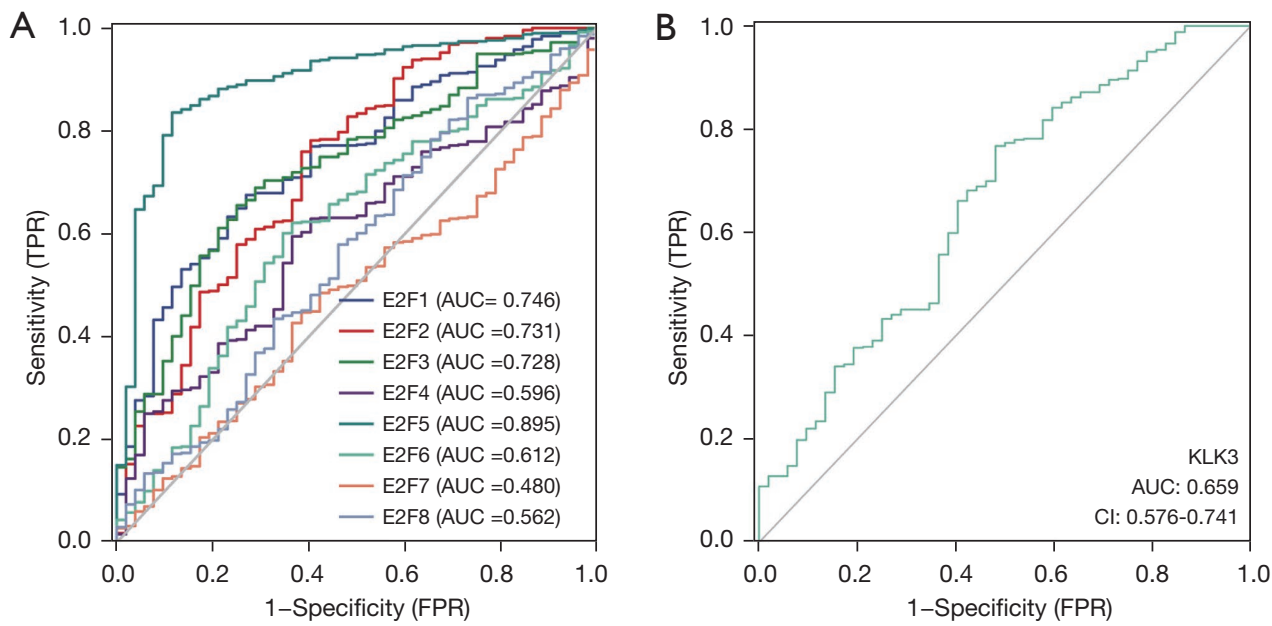

Figure 4 The ROC curves of E2F transcription factors (A) and PSA (B) in PCa. PSA, prostate specific antigen; KLK3, kallikrein related peptidase 3 , it is the gene name of PSA.

\section{The associations between E2Fs and immune cell infiltration}

We used TIMER to estimate the relationships between the expression levels of E2Fs and immune cell infiltration in patients with PCa (Figure 7). We found that the expression level of $E 2 F 1$ was negatively associated with the infiltration levels of $\mathrm{B}$ cells, $\mathrm{CD} 8^{+} \mathrm{T}$ cells, and neutrophils, and positively associated with $\mathrm{CD} 4^{+} \mathrm{T}$ cells, $\mathrm{T}$ regulatory cells, and macrophages. E2F2 was negatively associated with B cells, but positively associated with the other 5 kinds of immune cells. $E 2 F 3$ was positively associated with all 6 kinds of immune cells. In regard to E2F4, there existed a negative association between the expression levels of E2F4 and infiltration levels of $\mathrm{CD} 8^{+} \mathrm{T}$ cells and $\mathrm{T}$ regulatory cells, while the expression levels of E2F4 were positively associated with the other 4 kinds of cells. E2F5 and E2F6 were negatively associated with $\mathrm{B}$ cells and $\mathrm{CD} 8^{+} \mathrm{T}$ cells, while they were positively associated with the other 4 kinds of cells. E2F7 and E2F8 were both negatively associated with $\mathrm{CD} 8^{+} \mathrm{T}$ cells and positively associated with the other 5 kinds of cells.

\section{Experimental validation of human prostate cancer tissue}

In order to verify the above results, 23 paired cancer and adjacent tissues collected from patients with PCa were selected for real-time polymerase chain reaction (RT-PCR) detection to examine the expression of E2Fs in PCa. It was found that in cancer tissues, the expression levels of $E 2 F 1$ $E 2 F 3$ and $E 2 F 5$ were higher than those of adjacent tissues
$(\mathrm{P}<0.05)$, while the expression levels of E2F4 and E2F6 were lower than those of adjacent tissues (Figure 8). There was no statistically significant difference in the expression of $E 2 F 7$ and $E 2 F 8$ between cancer and adjacent normal tissues. The above results are consistent with the results from both TCGA database and Oncomine database.

\section{Discussion}

As important transcription factors, members of the E2F transcription factor protein family play a key role in regulating downstream gene transcription (13-17). Therefore, the abnormal expression of E2Fs in some tumors may play a dominant role in promoting or suppressing cancer by affecting a variety of downstream genes (18). The function of $E 2 F$ activators in the tumorigenesis and prognosis of several kinds of cancers has been clearly demonstrated $(19,20)$, but further analysis of their roles in PCa has not been elaborated. Our study investigated the expression of E2Fs and their clinical, diagnostic, prognostic, functional, and immunological value in patients with PCa. Our findings may help improve the treatment of patients with PCa.

The roles of each member of the $E 2 F$ family in tumorigenesis and the development of tumors have been reported, among which E2F1 is the most explored member (21-27). Previous research found that E2F1 can play various roles in different cancers (28). It has recently been reported that safranal inhibits cell cycle re-entry of quiescent PCa cells by deregulating the transcriptional activity of 


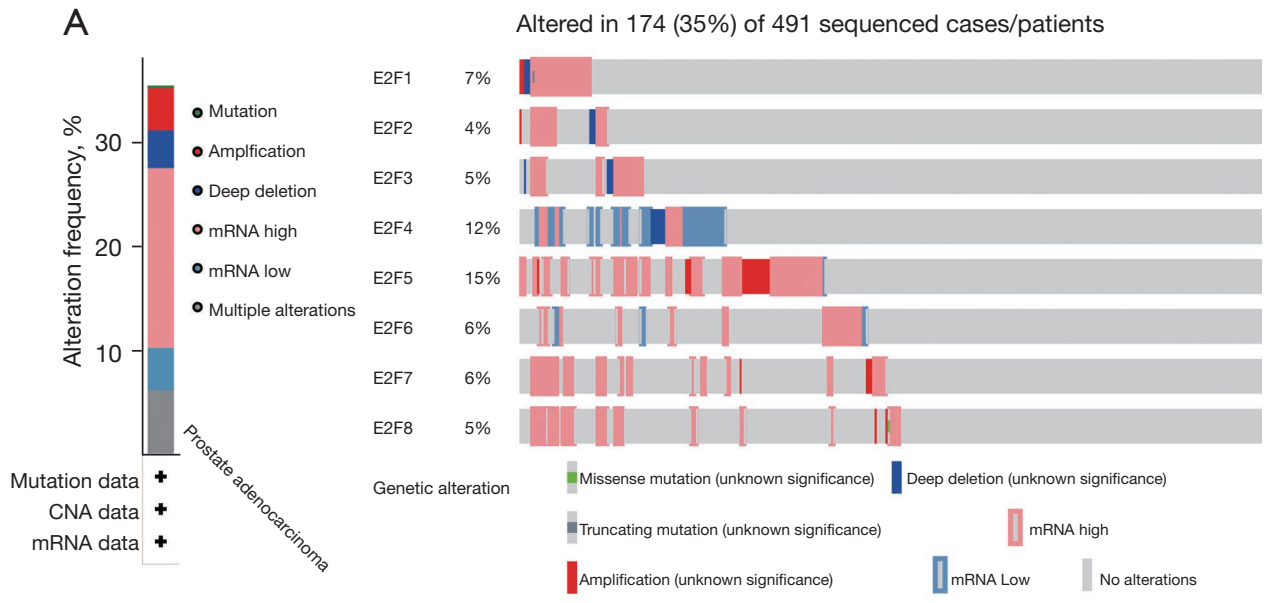

B

\begin{tabular}{|l|c|c|c|c|c|c|c|c|}
\hline & E2F1 & E2F2 & E2F3 & E2F4 & E2F5 & E2F6 & E2F7 & E2F8 \\
\hline E2F1 & 1 & 0.75 & 0.13 & 0.08 & 0.12 & -0.06 & 0.42 & 0.44 \\
\hline E2F2 & 0.75 & 1 & 0.35 & -0.01 & 0.27 & -0.06 & 0.63 & 0.64 \\
\hline E2F3 & 0.13 & 0.35 & 1 & -0.23 & 0.52 & 0.03 & 0.44 & 0.49 \\
\hline E2F4 & 0.08 & -0.01 & -0.23 & 1 & -0.36 & 0.19 & -0.11 & -0.17 \\
\hline E2F5 & 0.12 & 0.27 & 0.52 & -0.36 & 1 & -0.19 & 0.39 & 0.41 \\
\hline E2F6 & -0.06 & -0.06 & 0.19 & 0.19 & -0.19 & 1 & -0.12 & -0.08 \\
\hline E2F7 & 0.42 & 0.63 & -0.11 & -0.11 & 0.39 & -0.12 & 1 & 0.67 \\
\hline E2F8 & 0.44 & 0.64 & -0.17 & -0.17 & 0.41 & -0.08 & 0.67 & 1 \\
\hline
\end{tabular}

C

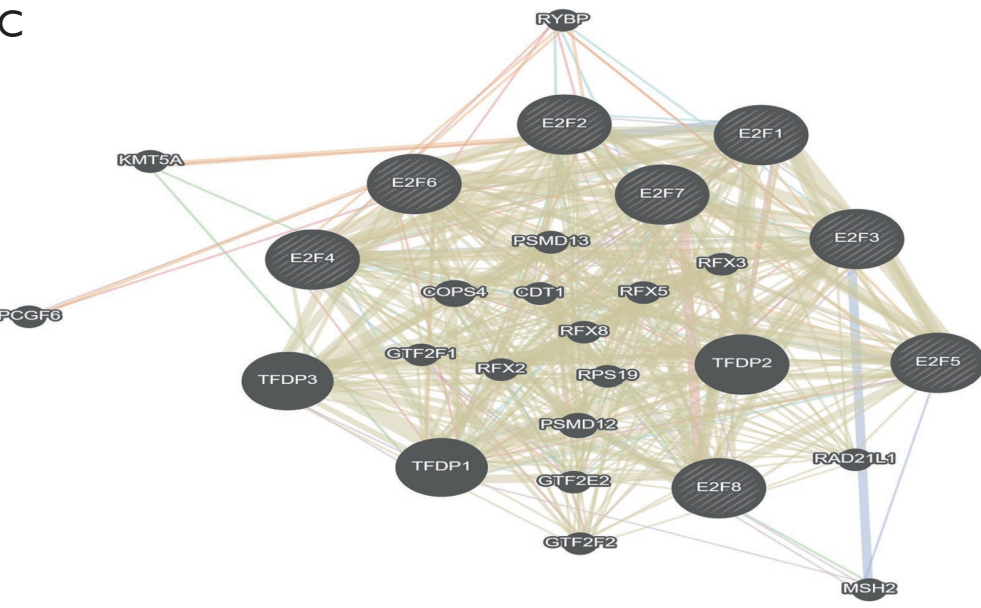

Figure 5 Genetic alteration, correlation analysis and neighbor gene network of E2F transcription factors in patients with PCa. (A) Summary of alterations of E2F transcription factors; (B) correlation heat map of E2F transcription factors; (C) neighbor gene network of E2F transcription factors. 

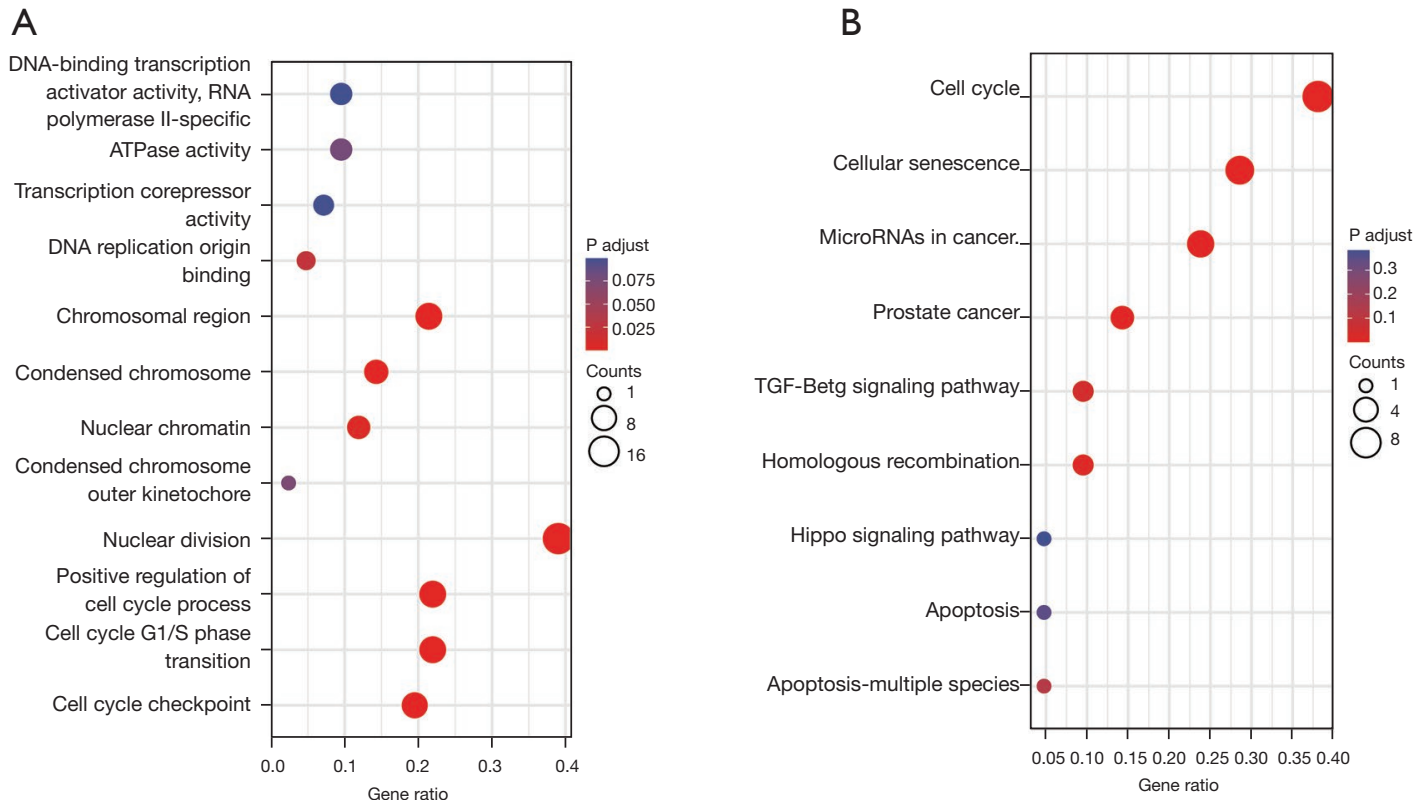

Figure 6 (A) Gene Ontology analysis and (B) Kyoto Encyclopedia of Gene and Genomes pathway analysis.

E2F1 (29). Hagiwara et al. indicated that through the integration of E2F1 and esBAF, MUC1-C facilitates the progression of neuroendocrine $\mathrm{PCa}$ (30). Altayyar et al. reported that $E 2 F 1$ is a translational target of WDR77 and is reactivated during PCa (31). Yang et al. demonstrated that high expression of E2F1 is associated with unfavorable prognosis in PCa cells (32). The study by $\mathrm{Xu}$ et al. showed that $E 2 \mathrm{~F} 1$ was markedly up in cancer and plays a key role in cellular inhibition when it is down-regulated (33). Qi et al. showed that in PCa cells, E2F1 participates in epithelial mesenchymal transition (EMT) (34). Wang et al. showed that the E2F1 pathway, which contributes to cell cycle arrest at the G0/G1 phase, promoted the radiosensitivity of PCa cells (35). Koushyar et al. demonstrated that $E 2 F 1$ leads to cell cycle progression in $\mathrm{PCa}$ (36). It was also reported that $R B$ loss can result in $E 2 F 1$ cistrome up-regulation and different binding specificity (37). In our study, the database analysis showed that the transcription level of E2F1 in PCa was significantly higher than that in normal prostate tissues both in paired samples or unpaired samples. Moreover, the expression level of $E 2 F 1$ increased with the progression of tumors, and significant differences existed in various stages of patients with PCa. There were also significant differences in the expression levels of E2F1 in patients with distinct ages and serum levels of PSA. Kaplan-Meier analysis found that high E2F1 transcription levels were markedly related to the OS of patients with $\mathrm{PCa}$.

Like E2F1, E2F2 can play opposing roles in causing and suppressing cancer. On the one hand, down-regulated expression of E2F2 can induce cell cycle arrest at the G1/ $\mathrm{S}$ phase and thus suppress cellular proliferation (38). On the other hand, through the inhibition of cell growth via G1 arrest, silibinin can lead to differentiation of androgendependent $\mathrm{LNCaP}$ cells (39). In our report, we found that the expression of E2F2 in human PCa was higher in both paired and unpaired samples. Furthermore, the expression of E2F2 was associated with tumor stage and lymph node stage in patients with $\mathrm{PCa}$.

High expression of $E 2 F 3$ is a cancer-promoting event for many cancers including $\mathrm{PCa}$, and is pivotal to tumor cell proliferation and the cell cycle (40). Altayyar et al. identified that $E 2 F 3$ is a translational target of $W D R 77$ and is reactivated during PCa (31). Previous studies have indicated that compared with tissues adjacent to $\mathrm{PCa}$, the E2F3 protein is overexpressed in clinical PCa samples, and the silencing of E2F3 suppresses the proliferation, migration, and invasion of PCa cells (41). Sun et al. showed that through targeting $E 2 F 3$, GA suppresses the growth of PCa cells (42), while O'Bryant et al. found that through inhibiting $E 2 F 3$, prostate-specific deletion of WDR77 inhibited prostate tumorigenesis (43). The data analysis showed that the E2F3 expression in PCa was significantly higher than that in normal tissues, and it was also correlated 

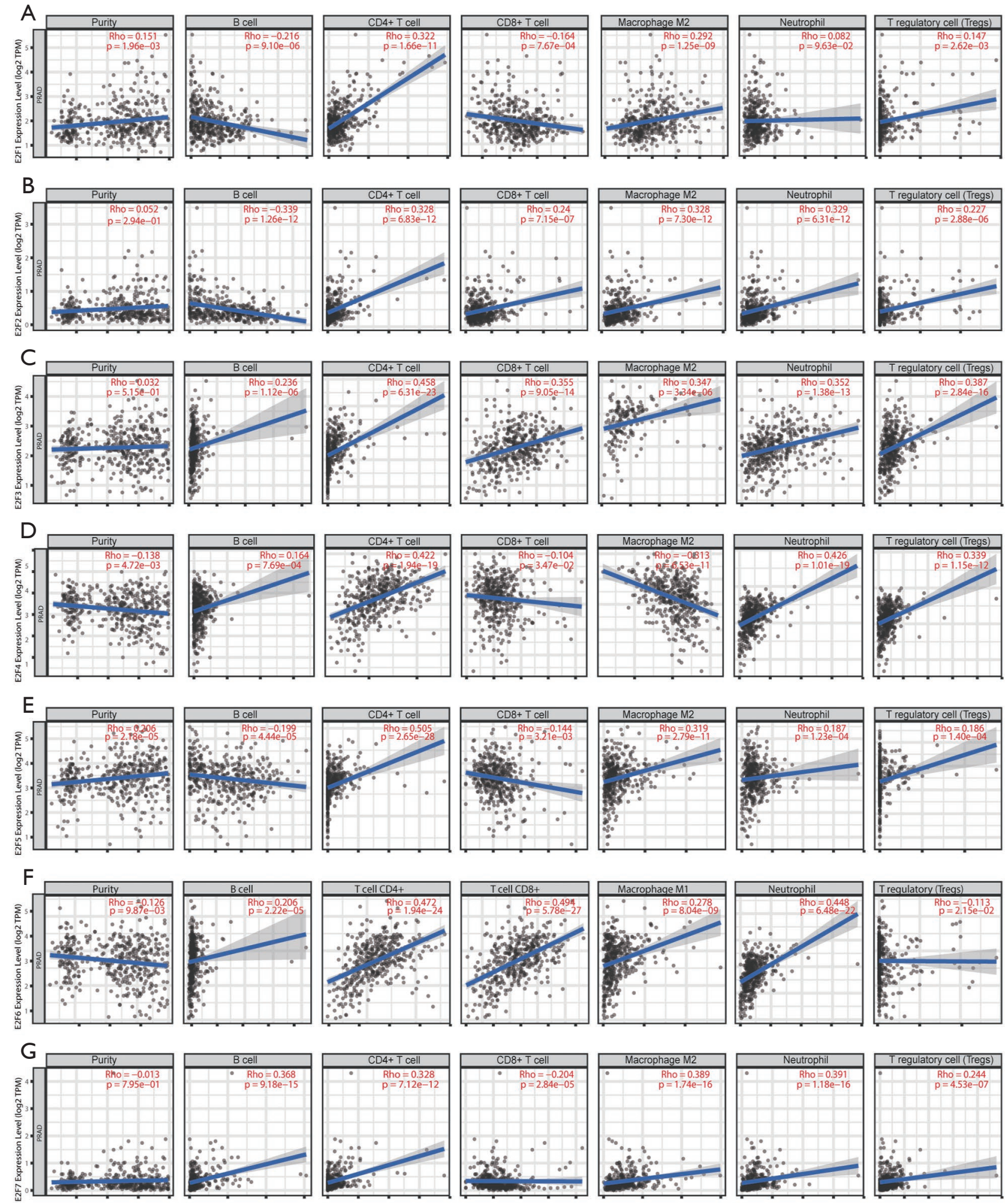

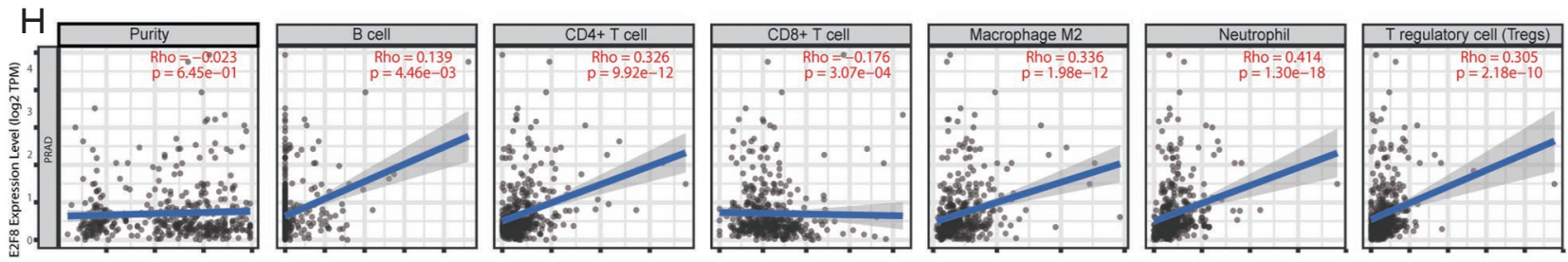

Figure 7 The correlation between E2F transcription factors and immune cell infiltration. (A) E2F1 was negatively associated with the infiltration levels of $\mathrm{B}$ cells, $\mathrm{CD} 8^{+} \mathrm{T}$ cells, and neutrophils, and positively associated with $\mathrm{CD} 4^{+} \mathrm{T}$ cells, $\mathrm{T}$ regulatory cells, and macrophages; (B) E2F2 was negatively associated with B cells, but positively associated with the other 5 kinds of immune cells; (C) E2F3 was positively associated with all 6 kinds of immune cells; (D) there existed a negative association between the expression levels of E2F4 and infiltration levels of $\mathrm{CD}^{+} \mathrm{T}$ cells and T regulatory cells, while the expression levels of E2F4 were positively associated with the other 4 kinds of cells; (E) E2F5 and (F) E2F6 were negatively associated with B cells and CD8 ${ }^{+} \mathrm{T}$ cells, while they were positively associated with the other 4 kinds of cells. (G) E2F7 and (H) E2F8 were both negatively associated with CD8 ${ }^{+} \mathrm{T}$ cells and positively associated with the other 5 kinds of cells.
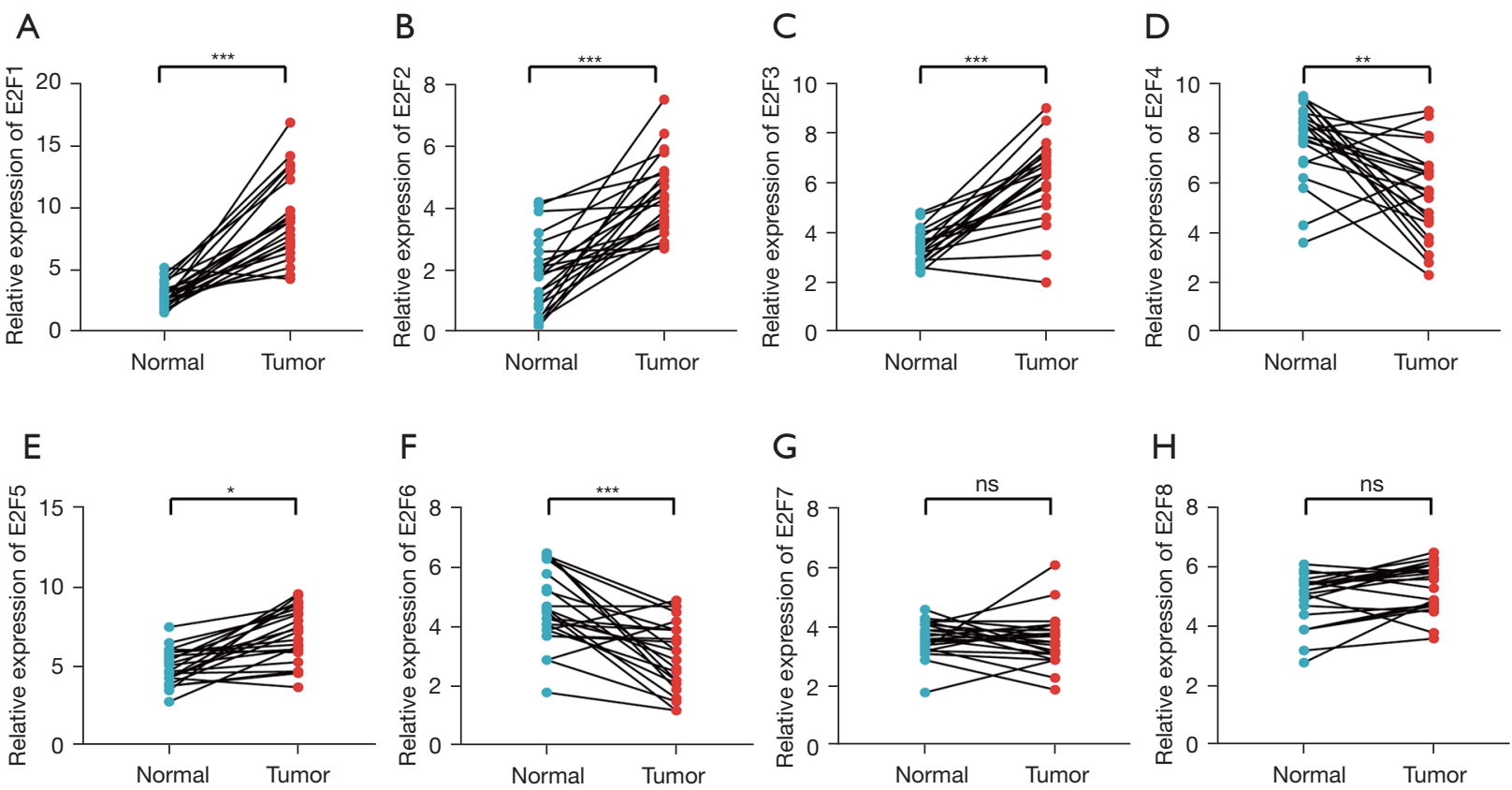

Figure 8 The expression levels of E2F transcription factors in 23 paired samples of PCa. The expression levels of E2F1-E2F3 and E2F5 were higher than those of adjacent tissues $(\mathrm{P}<0.05)(\mathrm{A}, \mathrm{B}, \mathrm{C}, \mathrm{E})$, while the expression levels of E2F4 (D) and E2F6 (F)were lower than those of adjacent tissues. There was no statistically significant difference in the expression of E2F7 (G) and E2F8 (H) between cancer and adjacent normal tissues. ${ }^{*} \mathrm{P}<0.05 ;{ }^{* *} \mathrm{P}<0.01 ;{ }^{* *} \mathrm{P}<0.001$. ns, not statistically significant.

with tumor stage.

E2F4, enriched in differentiated and nonproliferating cells, plays critical roles in the suppression of proliferationassociated genes (44). The results of the above study show that colon cancer, kidney cancer, and lung cancer are associated with high levels of E2F4. Li et al. demonstrated that through translocating from the cytoplasm to the nucleus,
E2F4 subsequently suppresses the transcription of cyclin $\mathrm{B} 1$ and the progression of the cell cycle (45). DuPree $e t$ al. found that the levels of E2F4 protein increased significantly in the nuclei of PCa cells (46). However, Yang et al. showed that TGF- $\beta$ reduces survivin expression in PCa epithelial cells by a mechanism of transcriptional suppression of E2F4 (47). Also, Crosby et al. showed that E2F4, in response 
to radiation, enhances stable G2 arrest by repressing the target genethus affording increased cell survival ability in PCa (48). In this study, we found that the mRNA level of E2F4 was markedly lower in PCa tissues than in normal tissues, yet it was obviously related to stages of $\mathrm{PCa}$. The expression level of $E 2 F 4$ is inversely related to OS.

Previous studies have found that E2F5 shows higher expression in certain kinds of tumors, including PCa (49,50). Li et al. reported that the up-regulation of microRNA-132 causes the down-regulation of $E 2 F 5$, which may contribute to the tumorigenesis of $\mathrm{PCa}(10)$. Zhao et al. indicated that the overexpression of the $E 2 F 5$ protein was obviously correlated with a higher Gleason score, positive metastasis, advanced clinical stage, and PSA failure (51). Li et al. found that through suppressing $E 2 F 5$, the tumor repressor miR$1-3 \mathrm{p}$ regulates the aggressiveness of $\mathrm{PCa}$ cells (52). Qi et al. showed that through enhancing CDK13 transcription, E2F5 leads to the up-regulation of its expression and the proliferation of PCa cells (49). Karmakar et al. provided strong evidence that by regulating the level and activity of its downstream targets, $E 2 F 5$ overexpression accelerates cell invasion and migration in $\mathrm{PCa}$ (50). In the present study, we showed that the mRNA level of E2F5 in PCa is obviously distinct from that in normal tissues.

Some studies have reported the role of E2F6 in PCa. Knockdown of E2F6 enhances the sensitivity of PCa cells to apoptosis induced by docetaxel (53). Similarly, Bhatnagar et al. reported that miR-205 and miR-31 downregulate E2F6 to enhance the PCa cell apoptosis induced by chemotherapeutics (54). The results from our analysis found that the mRNA level of E2F6 in human PCa is markedly different from that in normal tissues. However, survival analysis found that high mRNA expression of E2F6 resulted in worse OS in PCa patients but was not associated with tumor staging in PCa patients.

Recent studies have shown that $E 2 F 7$ functions as a transcriptional repressor and is up-regulated in many tumors. $E 2 F 7$ was mostly expressed both in the nuclei of poorly differentiated PCa tissues and in the cytoplasm of moderately or highly differentiated PCa tissues. In PCa cell lines, inhibiting the expression of $E 2 F 7$ reduces the cell proliferation rate, increases the proportion of cells in the G1 phase of the cell cycle, and boosts the apoptosis rate (12). He et al. indicated the cell cycle gene E2F7, expression of ARV-PBS target genes, was significantly associated with poor survival and tumor progression (55). However, this study found that there was no difference in the transcription level of E2F7 between PCa and normal tissues, although it had an influence on the stage of tumors. Also, survival analysis found that the expression of $E 2 F 7$ had no effect on OS in PCa patients.

As for $E 2 F 8$, little is currently known about its expression and role in $\mathrm{PCa}$. Lee et al. indicated that overexpression of E2F8 was related to PCa metastasis and that the downregulation of $E 2 F 8$ was able repress cell growth by enhancing G2/M arrest (56). In our report, as with $E 2 F 7$, there was no difference in the transcription level of $E 2 F 8$ between $\mathrm{PCa}$ and normal tissues despite it having an influence on tumor stage. However, survival analysis found that high $E 2 F 8$ mRNA expression resulted in worse OS in PCa patients.

\section{Conclusions}

This is the first study to systematically perform a comprehensive analysis of the expression and prognostic value of E2Fs in PCa. The aim of this research was to provide a better understanding of the $E 2 F$ family in the diversity of PCa from various aspects, such as the clinical, histopathological, and biomolecular characteristics. Our results suggest that the up-regulation of $E 2 F 1 / 2 / 3 / 5$ and the down-regulation of E2F4/6 in PCa tissues may play important roles in $\mathrm{PCa}$ tumorigenesis. Highly expressed E2F1/2/3/5/7 can be regarded as a molecular marker to identify high-risk PCa patients. Our findings revealed that E2F1/4/6/8 are potential treatment targets for PCa. In conclusion, the above results indicate that E2Fs may act as promising biomarkers for PCa. However, it is necessary to further study the molecular mechanisms, focusing on a single $E 2 F$ or a combination of several $E 2 F$ s, in order to promote the clinical application of E2Fs as prognostic indicators or treatment target for PCa.

\section{Acknowledgments}

We would like to thank C. Betlazar-Maseh and J. Gray for their help in polishing our paper.

Funding: None.

\section{Footnote}

Reporting Checklist: The authors have completed the REMARK reporting checklist. Available at https://dx.doi. org/10.21037/tcr-21-1532

Conflicts of Interest: All authors have completed the ICMJE 
uniform disclosure form (available at https://dx.doi. org/10.21037/tcr-21-1532). The authors have no conflicts of interest to declare.

Ethical Statement: The authors are accountable for all aspects of the work in ensuring that questions related to the accuracy or integrity of any part of the work are appropriately investigated and resolved. The study was conducted in accordance with the Declaration of Helsinki (as revised in 2013).

Open Access Statement: This is an Open Access article distributed in accordance with the Creative Commons Attribution-NonCommercial-NoDerivs 4.0 International License (CC BY-NC-ND 4.0), which permits the noncommercial replication and distribution of the article with the strict proviso that no changes or edits are made and the original work is properly cited (including links to both the formal publication through the relevant DOI and the license). See: https://creativecommons.org/licenses/by-nc-nd/4.0/.

\section{References}

1. Siegel RL, Miller KD, Jemal A. Cancer statistics, 2020. CA Cancer J Clin 2020;70:7-30.

2. Chen $\mathrm{W}$, Zheng $\mathrm{R}$, Baade $\mathrm{PD}$, et al. Cancer statistics in China, 2015. CA Cancer J Clin 2016;66:115-32.

3. McDonald AM, Jones JA, Cardan RA, et al. Combining Computed Tomography-Based Bone Density Assessment with FRAX Screening in Men with Prostate Cancer. J Clin Densitom 2016;19:430-5.

4. Stephenson AJ, Scardino PT, Eastham JA, et al. Postoperative nomogram predicting the 10-year probability of prostate cancer recurrence after radical prostatectomy. J Clin Oncol 2005;23:7005-12.

5. Kovesdi I, Reichel R, Nevins JR. Identification of a cellular transcription factor involved in E1A trans-activation. Cell 1986;45:219-28.

6. Kent LN, Leone G. The broken cycle: E2F dysfunction in cancer. Nat Rev Cancer 2019;19:326-38.

7. Oshi M, Takahashi H, Tokumaru Y, et al. The E2F Pathway Score as a Predictive Biomarker of Response to Neoadjuvant Therapy in ER+/HER2- Breast Cancer. Cells 2020;9:1643.

8. Xing J, Bhuria V, Bui KC, et al. Haprolid Inhibits Tumor Growth of Hepatocellular Carcinoma through Rb/E2F and Akt/mTOR Inhibition. Cancers (Basel) 2020;12:615.

9. Shackney SE, Chowdhury SA, Schwartz R. A Novel Subset of Human Tumors That Simultaneously Overexpress Multiple E2F-responsive Genes Found in Breast, Ovarian, and Prostate Cancers. Cancer Inform 2014;13:89-100.

10. Li SL, Sui Y, Sun J, et al. Identification of tumor suppressive role of microRNA-132 and its target gene in tumorigenesis of prostate cancer. Int J Mol Med 2018;41:2429-33.

11. Marczok S, Bortz B, Wang C, et al. Comprehensive Analysis of Genome Rearrangements in Eight Human Malignant Tumor Tissues. PLoS One 2016;11:e0158995.

12. Wang Y, Pei X, Xu P, et al. E2F7, regulated by miR-30c, inhibits apoptosis and promotes cell cycle of prostate cancer cells. Oncol Rep 2020;44:849-62.

13. Müller S, Bley N, Busch B, et al. The oncofetal RNA-binding protein IGF2BP1 is a druggable, posttranscriptional super-enhancer of E2F-driven gene expression in cancer. Nucleic Acids Res 2020;48:8576-90.

14. Emanuele MJ, Enrico TP, Mouery RD, et al. Complex Cartography: Regulation of E2F Transcription Factors by Cyclin F and Ubiquitin. Trends Cell Biol 2020;30:640-52.

15. Moreno E, Toussaint MJM, van Essen SC, et al. E2F7 Is a Potent Inhibitor of Liver Tumor Growth in Adult Mice. Hepatology 2021;73:303-17.

16. Sladky VC, Knapp K, Soratroi C, et al. E2F-Family Members Engage the PIDDosome to Limit Hepatocyte Ploidy in Liver Development and Regeneration. Dev Cell 2020;52:335-349.e7.

17. Clijsters L, Hoencamp C, Calis JJA, et al. Cyclin F Controls Cell-Cycle Transcriptional Outputs by Directing the Degradation of the Three Activator E2Fs. Mol Cell 2019;74:1264-1277.e7.

18. Johnson DG, Schneider-Broussard R. Role of E2F in cell cycle control and cancer. Front Biosci 1998;3:d447-8.

19. Chen $\mathrm{L}, \mathrm{Yu} J \mathrm{H}, \mathrm{Lu} \mathrm{ZH}$, et al. E2F2 induction in related to cell proliferation and poor prognosis in non-small cell lung carcinoma. Int J Clin Exp Pathol 2015;8:10545-54.

20. Park SA, Platt J, Lee JW, et al. E2F8 as a Novel Therapeutic Target for Lung Cancer. J Natl Cancer Inst 2015;107:djv151.

21. Tai MC, Kajino T, Nakatochi M, et al. miR-342$3 p$ regulates MYC transcriptional activity via direct repression of E2F1 in human lung cancer. Carcinogenesis 2015;36:1464-73.

22. Lai X, Gupta SK, Schmitz U, et al. MiR-205-5p and miR-342-3p cooperate in the repression of the E2F1 transcription factor in the context of anticancer chemotherapy resistance. Theranostics 2018;8:1106-20.

23. Wang T, Chen X, Qiao W, et al. Transcription factor 
E2F1 promotes EMT by regulating ZEB2 in small cell lung cancer. BMC Cancer 2017;17:719.

24. Li Z, Guo Y, Jiang H, et al. Differential regulation of MMPs by E2F1, Sp1 and NF-kappa B controls the small cell lung cancer invasive phenotype. BMC Cancer 2014;14:276.

25. Wu LC, Wen ZS, Qiu YT, et al. Largazole Arrests Cell Cycle at G1 Phase and Triggers Proteasomal Degradation of E2F1 in Lung Cancer Cells. ACS Med Chem Lett 2013;4:921-6.

26. Yu L, Fang F, Lu S, et al. lncRNA-HIT promotes cell proliferation of non-small cell lung cancer by association with E2F1. Cancer Gene Ther 2017;24:221-6.

27. Li ZL, Jiao F, Ma Y, et al. Target genes regulated by transcription factor E2F1 in small cell lung cancer. Sheng Li Xue Bao 2016;68:276-84.

28. Zhan L, Zhang Y, Wang W, et al. E2F1: a promising regulator in ovarian carcinoma. Tumour Biol 2016;37:2823-31.

29. Jiang X, Li Y, Feng JL, et al. Safrana 1 Prevents Prostate Cancer Recurrence by Blocking the Re-activation of Quiescent Cancer Cells via Downregulation of S-Phase Kinase-Associated Protein 2. Front Cell Dev Biol 2020;8:598620.

30. Hagiwara M, Yasumizu Y, Yamashita N, et al. MUC1-C Activates the BAF (mSWI/SNF) Complex in Prostate Cancer Stem Cells. Cancer Res 2021;81:1111-22.

31. Altayyar MA, Sheng X, Wang Z. WD Repeat Domain 77 Protein Regulates Translation of E2F1 and E2F3 mRNA. Mol Cell Biol 2020;40:e00302-20.

32. Yang L, Jin M, Park SJ, et al. SETD1A Promotes Proliferation of Castration-Resistant Prostate Cancer Cells via FOXM1 Transcription. Cancers (Basel) 2020;12:1736.

33. Xu J, Yang X, Deshmukh D, et al. The Role of Crosstalk between AR3 and E2F1 in Drug Resistance in Prostate Cancer Cells. Cells 2020;9:1094.

34. Qi JC, Yang Z, Zhang YP, et al. miR-20b-5p, TGFBR2, and E2F1 Form a Regulatory Loop to Participate in Epithelial to Mesenchymal Transition in Prostate Cancer. Front Oncol 2020;9:1535.

35. Wang F, Mao A, Tang J, et al. microRNA-16-5p enhances radiosensitivity through modulating Cyclin D1/E1-pRbE2F1 pathway in prostate cancer cells. J Cell Physiol 2019;234:13182-90.

36. Koushyar S, Economides G, Zaat S, et al. The prohibitinrepressive interaction with $\mathrm{E} 2 \mathrm{~F} 1$ is rapidly inhibited by androgen signalling in prostate cancer cells. Oncogenesis 2017;6:e333.
37. McNair C, Xu K, Mandigo AC, et al. Differential impact of $\mathrm{RB}$ status on $\mathrm{E} 2 \mathrm{~F} 1$ reprogramming in human cancer. J Clin Invest 2018;128:341-58.

38. Dong Q, Meng P, Wang T, et al. MicroRNA let-7a inhibits proliferation of human prostate cancer cells in vitro and in vivo by targeting E2F2 and CCND2. PLoS One 2010;5:e10147.

39. Tyagi A, Agarwal C, Agarwal R. Inhibition of retinoblastoma protein $(\mathrm{Rb})$ phosphorylation at serine sites and an increase in $\mathrm{Rb}-\mathrm{E} 2 \mathrm{~F}$ complex formation by silibinin in androgen-dependent human prostate carcinoma $\mathrm{LNCaP}$ cells: role in prostate cancer prevention. Mol Cancer Ther 2002;1:525-32.

40. Lees JA, Saito M, Vidal M, et al. The retinoblastoma protein binds to a family of E2F transcription factors. Mol Cell Biol 1993;13:7813-25.

41. Hu YM, Lou XL, Liu BZ, et al. TGF- $\beta 1$-regulated miR3691-3p targets E2F3 and PRDM1 to inhibit prostate cancer progression. Asian J Androl 2021;23:188-96.

42. Sun Y, Jiang M, Park PH, et al. Transcriptional suppression of androgen receptor by $18 \beta$-glycyrrhetinic acid in LNCaP human prostate cancer cells. Arch Pharm Res 2020;43:433-48.

43. O'Bryant $D$, Wang $Z$. The essential role of WD repeat domain 77 in prostate tumor initiation induced by Pten loss. Oncogene 2018;37:4151-63.

44. Rakha EA, Pinder SE, Paish EC, et al. Expression of E2F4 in invasive breast carcinomas is associated with poor prognosis. J Pathol 2004;203:754-61.

45. Li Y, Zhang DY, Ren Q, et al. Regulation of a novel androgen receptor target gene, the cyclin B1 gene, through androgen-dependent E2F family member switching. Mol Cell Biol 2012;32:2454-66.

46. DuPree EL, Mazumder S, Almasan A. Genotoxic stress induces expression of $\mathrm{E} 2 \mathrm{~F} 4$, leading to its association with p130 in prostate carcinoma cells. Cancer Res 2004;64:4390-3.

47. Yang J, Song K, Krebs TL, et al. Rb/E2F4 and Smad2/3 link survivin to TGF-beta-induced apoptosis and tumor progression. Oncogene 2008;27:5326-38.

48. Crosby ME, Jacobberger J, Gupta D, et al. E2F4 regulates a stable G2 arrest response to genotoxic stress in prostate carcinoma. Oncogene 2007;26:1897-909.

49. Qi JC, Yang Z, Lin T, et al. CDK13 upregulationinduced formation of the positive feedback loop among circCDK13, miR-212-5p/miR-449a and E2F5 contributes to prostate carcinogenesis. J Exp Clin Cancer Res 2021;40:2. 
50. Karmakar D, Maity J, Mondal P, et al. E2F5 promotes prostate cancer cell migration and invasion through regulation of TFPI2, MMP-2 and MMP-9. Carcinogenesis 2020;41:1767-80.

51. Zhao J, Wu XY, Ling XH, et al. Analysis of genetic aberrations on chromosomal region 8q21-24 identifies E2F5 as an oncogene with copy number gain in prostate cancer. Med Oncol 2013;30:465.

52. Li SM, Wu HL, Yu X, et al. The putative tumour suppressor miR-1-3p modulates prostate cancer cell aggressiveness by repressing E2F5 and PFTK1. J Exp Clin Cancer Res 2018;37:219.

53. Zhang Q, Padi SK, Tindall DJ, et al. Polycomb protein

Cite this article as: Wang D, Tang W, Zhang P, Liu Z, Lyu F, Xiao Y, Ni D, Zhang P. Comprehensive analysis of the functional and prognostic value of $\mathrm{E} 2 \mathrm{~F}$ transcription factors in human prostate cancer through data mining and experimental validation. Transl Cancer Res 2021;10(12):5095-5109. doi: $10.21037 /$ tcr-21-1532
EZH2 suppresses apoptosis by silencing the proapoptotic miR-31. Cell Death Dis 2014;5:e1486.

54. Bhatnagar N, Li X, Padi SK, et al. Downregulation of miR-205 and miR-31 confers resistance to chemotherapyinduced apoptosis in prostate cancer cells. Cell Death Dis 2010;1:e105.

55. He Y, Lu J, Ye Z, et al. Androgen receptor splice variants bind to constitutively open chromatin and promote abiraterone-resistant growth of prostate cancer. Nucleic Acids Res 2018;46:1895-911.

56. Lee S, Park YR, Kim SH, et al. Geraniol suppresses prostate cancer growth through down-regulation of E2F8. Cancer Med 2016;5:2899-908. 